\title{
Dynamic contour tonometry vs. non-contact tonometry and their relation with corneal thickness
}

\author{
Adriana Briceño, MsC; David Mas, PhD; Begoña Doménech, PhD. \\ Departamento de Óptica, Farmacología y Anatomía. Universidad de Alicante. San Vicente \\ del Raspeig, Alicante. Spain \\ E-mail: b.domenech@ua.es
}

\begin{abstract}
The purpose of this study is to evaluate the concordance between intraocular pressure (IOP) values obtained with a dynamic contour tonometer (DCT) and a non-contact tonometer (NCT) in healthy patients and to investigate the effect of central corneal thickness (CCT) on IOP readings for each of the two measuring systems. The mean IOP yielded by DCT, NCT and corrected non-contact tonometer (CNCT) was $17.1 \mathrm{mmHg}, 15.5 \mathrm{mmHg}$ and $12.2 \mathrm{mmHg}$, respectively. The average CCT was $563.6 \mu \mathrm{m}$ and the ocular pulse amplitude (OPA) was $2.8 \mathrm{mmHg}$. There was a moderate correlation between CCT and CNCT $(r=0.34, p=0.001)$, a weak correlation between CCT and DCT $(r=0.03 p=0.788)$ and a weak-to-moderate correlation between CCT and NCT $(r=0.27, p=0.11)$. The intra-class correlation coefficient (ICC) was 0.59 for the DCT-vs.-NCT comparison and 0.56 for DCT-vs.-CNCT. The mean difference between the two instruments (DCT / NCT) ranged from 1.62 to $4.47 \mathrm{mmHg}$. We have shown that non-contact tonometer is significantly more affected by the central corneal thickness than the dynamic contour tonometer and therefore these methods are not interchangeable.
\end{abstract}

Keywords: Intraocular pressure; corneal thickness; dynamic contour tonometry; non-contact tonometry; tonometry correction factors 


\section{1.- Introduction}

Biomechanical properties of the eye are of fundamental importance for proper model design, planning of surgical intervention, pharmacological interaction or even risk control of ocular pathologies. Among these properties, the intraocular pressure is, by far, one of the most known and studied physical parameters of the eye.

Intraocular pressure (IOP) is the main risk factor for glaucoma development and subsequent evolution, which is the leading cause of irreversible blindness in the world [1]. There are numerous systems to measure IOP. Among them, Goldman applanation tonometry (GAT) is still considered the gold standard although it is well-known that the IOP readings that this system yields are dependent on the corneal biomechanical properties of the eye under assessment, and particularly on the central corneal thickness (CCT), the corneal curvature and potential corneal surface irregularities [2,3]. Moreover, the advent of refractive surgery aroused even more the interest in this discussion, since due to the changes undergone by the corneal structure as a result of the surgical procedure it has been demonstrated that post-operative IOP is underestimated when using GAT as measuring technique, which can lead to an erroneous assessment (false negatives). Similarly, the system overestimates IOP values in eyes having thick corneas, which could lead to a wrong diagnosis of ocular hypertension (false positives). Therefore, in the past few years efforts have been made to develop alternative IOP measuring systems that are less dependent on corneal features [4]. Among those alternative methods we will focus on two specific ones in this study: The non- 
contact tonometer (NCT, also called air-puff tonometer) and the dynamic contour tonometer (DCT, also known as Pascal tonometer).

The NCT uses a puff of air to flatten (applanate) the cornea. Once initiated, the puff force increases linearly until it causes a temporary applanation of the cornea over a predetermined area. This technique's advantage, compared to GAT, is that the system doesn't need to come into contact with the cornea and, hence, no topical anesthesia needs to be instilled. Even though there is a good correlation between this tonometer's IOP readings and GAT's readings, especially in patients having thin corneas, in patients with thicker corneas the non-contact tonometer tends to yield higher values than GAT. The NCT has been recently included in a new device-Visionix $V \times 120-$, which is a multifunctional platform with which IOP can be measured while applying different CCT-related correction factors.

On the other hand, DCT is a non-applanation tonometer that continuously measures IOP for short periods of time, and that is based on the direct detection of trans-corneal pressure. The physical principle it relies on is different from GAT's; DCT has a concave-shaped sensor tip that adapts to the corneal surface contour while maintaining its shape and curvature and causing minimum distortion, with no corneal applanation [5-9].

Different authors have evaluated this tonometer's reliability in terms of both its repeatability and its reproducibility as well as the agreement with other tonometers, particularly with GAT. These studies showed that DCT provides good intra- and within-subject repeatability and concordance $[6,7,10-13]$. 
DCT's IOP readings are less affected by CCT variations that those obtained with other tonometers [2, 3, 10, 11, 14-22].

As can be inferred form the Introduction the eye is a complex system whose properties are not easy to assess. Therefore, in order to better describe this system it is necessary to understand the limitations of the different measuring systems. Systematic inaccuracies or differences between the different tonometers may help to understand the interation between the eye and the measuring method and thus help to design more accurate devices.

Bearing this in mind, the aim of this study is to compare DCT and NCT IOP readings and to determine how dependent on corneal thickness the results are. Moreover, we will explore whether or not the Ehlers correction approach proposed by the NCT system's manufacturer is able to offset the effect of CCT and to yield more accurate IOP values.. Results here show that measurement from standard systems, even when they are widely accepted as correct, should be considered with caution.

\section{2.- Methods}

For the purpose of this study a convenience sample was selected, which was made up of 90 patients from the University of Alicante's Optometry Center. Only one eye from each patient was randomly selected to be included in the study. Patients showing corneal abnormalities were excluded from the study. Once the comprehensive ophthalmological and optometric examination was completed, two additional IOP measurements were carried out: one using the dynamic contour tonometer (DCT Pascal; Swiss Microtechnology AG, Port, Switzerland) and a second one with the VX120 platform (Visionix, Prunay le 
Guillon, France). The latter device, which combines a non-contact tonometer (NCT) and a Scheimpflug slit-lamp, is able to provide not only IOP data but also CCT values. DCT measurements were performed under ocular topical anesthesia. According to the manufacture's manual, only those readings having quality index $Q \leq 3$ were considered for further analysis. All the measurements were carried out by the same examiner. Once they were informed of their inclusion in the study all patients signed an informed consent document, in accordance with the ethical principles stated in the Declaration of Helsinki.

For the analysis of the refraction data Fourier's notation was employed. From the standard sphero-cylindrical formula with the positive-cylinder conventionsphere (S), cylinder (C) and axis $(\beta)$-the three coordinates of the power vector $\left(\mathrm{M}, \mathrm{J}_{0}, \mathrm{~J}_{45}\right)$ can be calculated as follows:

$M=S+C / 2$

$J_{0^{\circ}}=-C / 2 \operatorname{Cos} 2 \beta$

$J_{45^{\circ}}=-C / 2 \operatorname{Sin} 2 \beta$

Where $\mathrm{M}$ is the spherical equivalent, $\mathrm{J}_{0^{\circ}}$ represents the power of a Jackson cross-cylinder at 0 degrees and $\mathrm{J}_{45^{\circ}}$ is the power of a Jackson cross-cylinder having its axis at 45 degrees [23].

The statistical analysis was performed with the SPSS v15.0 software package for Windows (SPSS Inc., Chicago, IL., EE. UU.). The statistical data were shown to be normally distributed as demonstrated by means of the Kolmogorov-Smirnov test. The correlation between central corneal thickness (CCT) and intraocular pressure (IOP) was explored by computing Pearson's 
correlation coefficient $(r)$. The correlation between two variables is classified either as weak $(r<0.3)$, moderate ( $r$ between 0.3 and 0.7$)$ or strong $(r>0.7)$. Moreover, $p$-values below 0.05 were assumed to be statistically significant. To evaluate the concordance between DCT, NCT y CNCT (corrected non-contact tonometer) regarding IOP, the metric of choice was the intra-class correlation coefficient (ICC) for a 95\% confidence interval. Furthermore, we also computed the average of each pair of IOP measurements, together with its standard deviation (SD), the difference with its SD, the within-subject standard deviation (Sw) and the within-subject coefficient of variation (CVw $=100$

Sw/average). The ICC was rated according to Fermanian's classification, which states that concordance is excellent for ICC greater than 0.91 , good for ICC ranging from 0.90 to 0.71 , moderate for ICC ranging from 0.70 to 0.51 , fair for ICC ranging from 0.50 to 0,31 and bad for ICC lower than 0.30 [24].

Finally, the differences found across devices for IOP values were further analyzed using the Bland-Altman graphical method [25].

\section{RESULTS}

Table 1, which summarizes the main features of the 90 eyes included in the study — subject's refractive status, mean age and gender breakdown- also shows this study's main results: intraocular pressure (IOP) measured with the two systems under analysis as well as central corneal thickness (CCT) and ocular pulse amplitude (OPA) data. The table shows average and their corresponding standard deviation values, as well as the range between parentheses (for those parameters that represent real measurements). As can 
be seen from the table, the average CCT was $563.6 \pm 36.6 \mu \mathrm{m}$. The average IOP was $15.5 \pm 4.2 \mathrm{mmHg}$ when measured with the NCT, and $17.1 \pm 3.3 \mathrm{mmHg}$ when measured with the DCT. A correction factor was then applied to the IOP values yielded by the $\mathrm{V} x 120$ (NCT) so as to obtain the corrected non-contact tonometry data set (CNCT), leading to an average value of $12.2 \pm 4.3 \mathrm{mmHg}$. Lastly, the mean OPA was $2.8 \pm 1.15 \mathrm{mmHg}$.

Once all the individual data sets were obtained with the two tonometers under study, the association between IOP and CCT was explored, as shown in Table 2. As can be derived from the table, there is a minimal association between CCT and IOP measured with DCT $(r=0.03)$, while there is a moderate association between CCT and the IOP values obtained with the CNCT approach $(r=0.34)$. In this latter case, we can attribute to the CCT factor about $12 \%\left(R^{2}=0.118\right)$ of the IOP variation. This means that CCT only explains $11,8 \%$ of IOP variation. Lastly, the association between CCT and IOP measured with TNC is on the weak-moderate borderline $(r=0.27)$.

In order to have a more visual representation of these data, Figure 1 shows the scatter plots of IOP (top: NCT, middle: CNCT, and bottom: DCT) vs. CCT. As can be inferred from the middle plot, the correction suggested by the VX120 platform, which is based on central corneal thickness values (Ehlers correction), leads to a slope-sign reversal and to a stronger association between the two variables (increasing from weak to moderate). 
Table 3 summarizes the main findings of the IOP concordance analysis comparing DCT and NCT and DCT and CNCT. The resulting intra-class correlation coefficient (ICC) was 0.59 in the former case $(95 \% \mathrm{Cl}$ : $[0.445$ $0.715])$ and 0.56 in the latter case (95\% Cl: [0.399-0.686]). The mean difference between IOP measured with NCT and IOP measured with DCT is $1.62 \mathrm{mmHg}$, while the mean difference between DCT and CNCT values amounts to $4.95 \mathrm{mmHg}$. The consistency of IOP values yielded by the different methods under study has been further explored by means of the graphical Bland-Altman method. Figure 2 illustrates the concordance between DCT and NCT (top panel) and between DCT and CNCT (bottom panel). As can be seen from the top plot, the DCT-vs-NCT comparison has a wide concordance limit $(-2.85$ to $6.09 \mathrm{mmHg})$ with a range of $4.47 \mathrm{mmHg}$. As for the latter case (DCT-vs-CNCT, bottom plot), both the concordance interval (12.21 to $-2.31 \mathrm{mmHg})$ and the range $(7.26 \mathrm{mmHg})$ are greater than those found in the DCT-vs-NCT comparison.

\section{4.- Discussion}

Intraocular pressure (IOP), which is key for the diagnosis of ocular hypertension and glaucoma, must be accurately determined with a high level of accuracy [26]. Even though in this scenario Goldman tonometry is still the gold standard, different studies have revealed that the IOP values it provides are dependent on the corneal anatomical and morphological characteristics and, particularly, on the central corneal thickness. Ehlers [27], as well as other authors [14,15,28,29], have proposed different approaches (formulas) to compensate for this dependence. Nevertheless, there isn't yet a widely- 
accepted general formula that is valid for all populations and for all commercially-available tonometers.

Several studies have demonstrated that Pascal's dynamic contour tonometer (DCT) can be a reasonable alternative for routine IOP evaluation in clinical practice. This conclusion is supported by those studies that have assessed DCT's reliability and by those that have compared it with other tonometers and have estimated the influence of central corneal thickness on DCT's IOP readings $[2,3,10,11,14-22]$. Most of these studies conclude that DCT yields IOP values that are independent from (i.e., not biased by) the subject's CCT and, therefore, that are much closer to the true intraocular pressure.

In the present work IOP has been measured with two systems-DCT and NCT - that are based on different approaches. In the latter case we have analyzed both the device's raw data (NCT) and the corrected data (CNCT) using Ehlers' formula, which is considered by the tonometer's manufacturer as the most appropriate correction method.

Table 4 summarizes the main findings of previous studies found in the literature comparing DCT with other tonometers in terms of the influence of CCT on their IOP readings. Our results show a weak-to-moderate dependence for the non-contact tonometer $\left(r=0.27 ; R^{2}=0.071 ; p=0.11\right)$, which is lower than that obtained by Burvenich et al. $\left(r=0.4994 ; R^{2}=0.2494\right)$ in subjects with healthy eyes and that obtained by Erdurmus et al. in patients with ocular hypertension and glaucoma. 
It is worth pointing out that our study revealed a stronger dependence on CCT for the corrected IOP values (CNCT) than for the raw IOP data (NCT). In this particular case Ehlers' correction factor overestimates the influence of CCT on IOP values yielded by the non-contact tonometer, thus leading to a reversal effect in the scatter plot (i.e., change in the regression line's slope sign; see Figure 1), which shows a trend towards lower IOP values as CCT increases. This effect was also observed by Gunvant et al. when applying Ehlers' correction factor to GAT's IOP readings. That study's authors concluded that Ehlers nomogram overestimates the effect of CCT upon IOP readings and that other parameters, such as corneal rigidity and hydration, could also have an impact on corneal biomechanics and, therefore, they could represent additional sources of error.

As for the dependence of DCT-measured IOP on CCT, our results are in good agreement with most of the studies published to date in the literature (see Table 4). Our data analysis indicates that there is no association between IOP and CCT, both in terms of the p-value (0.788), which is well above the significance threshold, and in terms of the $r$ and $R^{2}$ coefficients resulting from the linear regression analysis. The only study in Table 4 that produced a significant $p$-value is that by Jordao et al., but the subsequent calculation of the Pearson's correlation coefficient also led them to conclude that there was no correlation between the two variables. As can be seen from the table, the studies were carried out in very different populations, both in terms of size and in terms of the participants' ocular health status. 
Regarding the side-by-side tonometer comparison, the present study has observed that DCT provides IOP readings that are, on average, $1,6 \mathrm{mmHg}$ higher than those provided by the NCT, which is similar to the findings by Erdumus et al., who concluded that NCT underestimates IOP values by $0.8 \mathrm{mmHg}$ compared to DCT. As for the concordance limits in the Erdumus study, they range from -6.6 to $5.1 \mathrm{mmHg}$. In our study these limits define a slightly narrower interval $(-2.85$ to $6.09 \mathrm{mmHg})$, which reveals significant clinical differences that confirm that DCT and NCT IOP values are not interchangeable. The paper by Burvenich et al. does not include an NCT-vsDCT comparison in terms of IOP values. However, there are numerous publications where DCT and GAT are compared by means of the BlandAltman method. All of them concluded that DCT yields higher IOP readings than GAT, the mean difference ranging between 0.7 and $4.4 \mathrm{mmHg}$ and the concordance limits being also very diverse. Jordao et al. obtained a concordance range of $10.45 \mathrm{mmHg}$, which is even larger than that obtained in the present study $(4.47 \mathrm{mmHg})$.

The DCT-vs-CNCT comparison yields even more unfavorable results: The Bland-Altman analysis (Figure 2, bottom) shows a mean difference of $4.95 \mathrm{mmHg}$ (i.e., CNCT provides, on average, lower IOP readings than the corresponding DCT values) and 95\% limits of agreement were [12.21 to $2.31 \mathrm{mmHg}$; the agreement range being $7.26 \mathrm{mmHg}$. All these data suggest that DCT and CNCT IOP values are not interchangeable, that there are 
relevant clinical differences and that applying Ehlers correction factor to NCT data has led to an overestimation of CCT's influence on IOP readings.

In the present work, besides using the Bland-Altman method, concordance has also been assessed by means of the intra-class correlation coefficient (ICC), the within-subject standard deviation (Sw) and the within-subject coefficient of variation $(\mathrm{CVW})$. Even though the resulting ICC values may suggest that there is a moderate concordance across tonometry methods (according to Fermanian's classification), considering the large 95\% confidence intervals we are more prone to rate the concordance as "weak to moderate". Sw and CVw values are not too good either, since they reveal a significant variability (greater than $25 \%$ ) between CNCT and DCT IOP values.

Among those papers found in the literature, the study that is closest to ours is that by Erdurmus et al., since they compared the same two tonometers that we evaluated and they also assessed for both instruments IOP-reading dependence on CCT value. However, our work provides additional statistical parameters to evaluate the concordance between data sets; i.e., the withinsubject coefficient of variation as well as the intra-class correlation coefficient for a $95 \%$ confidence interval. The resulting values for these parameters are in good agreement with the results of the Bland-Altman graphical analysis, which further supports the conclusion of a poor concordance between the two systems and, particularly, between DCT and CNCT. 
Another study involving the same two tonometers is that by Burvenich et al. but, as mentioned above, they didn't explore the concordance between the two devices.

In Erdurmus et al.'s work, as was the case in most studies shown in Table 4, CCT has been measured using ultrasound pachymetry, which is still considered the gold standard. Contrariwise, in the present work CCT was measured using the VX120 platform, which is based in Scheimpflug imaging, and the resulting mean CCT $(563.6 \pm 36.6 \mu \mathrm{m})$ agrees with the average CCT found across the other studies, where mean CCT ranges from $534 \mu \mathrm{m}$ (Jordao's study in glaucoma and ocular hypertension patients) to $594.5 \mu \mathrm{m}$ (Colás-Tomás et al.'s study in patients with ocular hypertension).

Our study was subject to certain limitations. No reliability studies have been published yet about the VX120 platform, which is the device used in this study to perform non-contact tonometry and pachymetry measurements. The proposed Ehlers correction doesn't seem to be appropriate for this platform's tonometer. Besides, the correction factor amounts in some cases up to $12 \mathrm{mmHg}$, which is much larger than the $3 \mathrm{mmHg}$ maximum error suggested in some papers or even than $7 \mathrm{mmHg}$, which is the maximum correction factor included in some of the tables that ophthalmologists use in their daily practice.

Another limitation has to do with the fact that the study population was a convenience sample. In this sense, we are not able to quantify its 
representativity and, hence, the results we have obtained in the present work cannot be generalized to a specific population.

All in all, our study shows that when it comes to measuring IOP, DCT is less dependent on CCT than NCT (both for raw and for corrected IOP values). It also concludes that the concordance between the two tonometers under assessment is not good. The differences between the two systems are clinically relevant, which implies that the two devices are not at all interchangeable. DCT can be an optimum alternative to the current gold standard (GAT) because it has been proven to be less dependent on corneal characteristics.

In our opinion, our results (and other similar to us) show that the ocular globe is a complex system that is far from being correctly understood. Therefore, we still find small discrepancies between the different methods that depend how the physical measuring system interacts with the specimen. Understanding these complex relations together with the limitation of each technique may help to understand the complex mechanism that regulates the intraocular pressure.

\section{REFERENCES}

[1] H. Quigley, A.T. Broman, The number of people with glaucoma worldwide in 2010 and 2020, Br. J. Ophthalmol. 90 (2006) 262-267 [2] J.M. Martinez-de-la-Casa, J. Garcia-Feijoo, E. Vico, A. Fernandez-Vidal, J.M. Benitez del Castillo, M. Wasfi, J. Garcia- 
Sanchez, Effect of Corneal Thickness on Dynamic Contour,

Rebound, and Goldmann Tonometry, Ophthalmology. 113 (2006) $2156-2162$.

[3] F. Sáenz-Francés, R. García-Catalán, M. Jerez-Fidalgo, A.

Fernández-Vidal, J.M. Martínez-De-La-Casa, C. Méndez-Hernández,

E. Santos-Bueso, J. Reche-Frutos, J. García-Sánchez, J. García-

Feijoo, Comparison of Goldmann applanation and dynamic contour tonometry measurements: Effects of corneal morphometry, Arch.

Soc. Esp. Oftalmol. 86 (2011) 287-291.

[4] C.G.V. De Moraes, T.S. Prata, J. Liebmann, R. Ritch, Modalities of tonometry and their accuracy with respect to corneal thickness and irregularities, Journal of Optometry. 1 (2008) 43-49.

[5] H.E. Kanngiesser, C. Kniestedt, Y.C.A. Robert, Dynamic contour tonometry: Presentation of a new tonometer, J. Glaucoma. 14 (2005) 344-350.

[6] M. Detry-Morel, J. Jamart, M.B. Detry, A. Ledoux, S. Pourjavan, Clinical evaluation of the Pascal $®$ dynamic contour tonometer, J. Fr. Ophtalmol. 30 (2007) 260-270.

[7] S. Herdener, D. Hafizovic, M. Pache, S. Lautebach, J. Funk, Is the PASCAL $®$-Tonometer suitable for measuring intraocular pressure in clinical routine? Long- and short-term reproducibility of dynamic contour tonometry, Eur. J. Ophthalmol. 18 (2008) 39-43. [8] H. Heras-Mulero, J. Moreno-Montañés, L.M. Sádaba Echarri, L. Mendiluce Martín, Comparison of dynamic contour tonometry 
(Pascal $®$ ) with pneumotonometry and Goldmann tonometry, Arch. Soc. Esp. Oftalmol. 82 (2007) 337-341.

[9] D.H. Erickson, D. Goodwin, M. Rollins, A. Belaustegui, C. Anderson, Comparison of dynamic contour tonometry and Goldmann applanation tonometry and their relationship to corneal properties, refractive error, and ocular pulse amplitude, Optometry. 80 (2009) 169-174.

[10] C. Kaufmann, L.M. Bachmann, M.A. Thiel, Comparison of dynamic contour tonometry with Goldmann applanation tonometry, Invest. Ophthalmol. Visual Sci. 45 (2004) 3118-3121.

[11] A. Kotecha, E.T. White, J.M. Shewry, D.F. Garway-Heath, The relative effects of corneal thickness and age on Goldmann applanation tonometry and dynamic contour tonometry, Br. J. Ophthalmol. 89 (2005) 1572-1575.

[12] M. Sullivan-Mee, G. Gerhardt, K.D. Halverson, C. Qualls, Repeatability and reproducibility for intraocular pressure measurement by dynamic contour, ocular response analyzer, and goldmann applanation tonometry, J. Glaucoma. 18 (2009) 666-673. [13] A.S. Wang, L.M. Alencar, R.N. Weinreb, A. Tafreshi, S. Deokule, G. Vizzeri, F.A. Medeiros, Repeatability and reproducibility of goldmann applanation, dynamic contour, and ocular response analyzer tonometry, J. Glaucoma. 22 (2013) 127-132.

[14] P. Ceruti, R. Morbio, M. Marraffa, G. Marchini, Comparison of Goldmann applanation tonometry and dynamic contour tonometry 
in healthy and glaucomatous eyes, Eye. 23 (2009) 262-269.

[15] B.A. Kamppeter, J.B. Jonas, Dynamic contour tonometry for intraocular pressure measurement, Am. J. Ophthalmol. 140 (2005) 318-320.

[16] M.L.S. Jordo, A. Pedroso De Carvalho Lupinacci, E.L. Ferreira, I.J.F. Enomoto, V.P. Costa, Influence of age, central corneal thickness, and quality score on dynamic contour tonometry, Eye. 23 (2009) 1364-1369.

[17] H. Burvenich, E. Burvenich, C. Vincent, Dynamic contour tonometry (DCT) versus non-contact tonometry (NCT): a comparison study. Bulletin de la Société belge d'ophtalmologie. (2005) 63-69.

[18] M. Erdurmus, Y. Totan, I.F. Hepsen, R. Yagci, Comparison of dynamic contour tonometry and noncontact tonometry in ocular hypertension and glaucoma, Eye. 23 (2009) 663-668. [19] M.L.S. Jordão, V.P. Costa, M.D.L.V. Rodrigues, J.S. Paula, Comparison of dynamic contour tonometry and Goldmann applanation tonometry in relation to central corneal thickness in primary congenital glaucoma, Graefe's Archive for Clinical and Experimental Ophthalmology. 251 (2013) 117-121.

[20] P. Gunvant, R.D. Newcomb, E.M. Kirstein, V.E. Malinovsky, R.J. Madonna, R.E. Meetz, Measuring accurate IOPs: Does correction factor help or hurt? Clinical Ophthalmology. 4 (2010) 611-616. [21] T. Colás-Tomás, M. Prieto-Del Cura, I. Villafruela-Güemes, A. 
Clariana-Martín, A. Valdivia-Pérez, Comparison of dynamic contour tonometry, Goldmann and pneumotonometer in ocular hypertension patients and their relationship to pachymetry and ocular pulse amplitude, Arch. Soc. Esp. Oftalmol. 87 (2012) 401-406.

[22] L. Barleon, E.M. Hoffmann, M. Berres, N. Pfeiffer, F.H. Grus, Comparison of Dynamic Contour Tonometry and Goldmann Applanation Tonometry in Glaucoma Patients and Healthy Subjects, Am. J. Ophthalmol. 142 (2006) 583-590.

[23] L.N. Thibos, W. Wheeler, D. Horner, Power vectors: An application of fourier analysis to the description and statistical analysis of refractive error, Optom. Vis. Sci. 74 (1997) 367-375. [24] J. Fermanian, Measurement of agreement between 2 judges. Qualitative cases, Rev. Epidemiol. Sante Publique. 32 (1984) 140147.

[25] J.M. Bland, D.G. Altman, Statistical methods for assessing agreement between two methods of clinical measurement, Lancet. 1 (1986) 307-310.

[26] P.-. Tonnu, T. Ho, T. Newson, A. El Sheikh, K. Sharma, E. White, C. Bunce, D.F. Garway-Heath, The influence of central corneal thickness and age on intraocular pressure measured by pneumotonometry, non-contact tonometry, the Tono-Pen $\mathrm{XL}$, and Goldmann applanation tonometry, Br. J. Ophthalmol. 89 (2005) 851-854.

[27] N. Ehlers, T. Bramsen, S. Sperling, Applanation tonometry and 
central corneal thickness, Acta Ophthalmol. 53 (1975) 34-43.

[28] P.-. Tonnu, T. Ho, K. Sharma, E. White, C. Bunce, D.F.

Garway-Heath, A comparison of four methods of tonometry: Method agreement and interobserver variability, Br. J. Ophthalmol. 89 (2005) 847-850.

[29] M.M. Whitacre, R.A. Stein, K. Hassanein, The effect of corneal

thickness on applanation tonometry, Am. J. Ophthalmol. 115 (1993) 592-596. 


\begin{tabular}{lc}
\hline Parameters & Mean \pm SD (range) \\
\hline $\mathbf{n}$ & 90 \\
Sex (M/F) & $47 / 43$ \\
Age (years) & \\
Eye (R/L) & $47.2 \pm 12.2(19-74)$ \\
Refractive error (D) & \\
$\mathbf{M}$ & $-1.40 \pm 3.40$ \\
$\mathbf{J}_{0}$ & $0.11 \pm 0.45$ \\
$\mathbf{J}_{45}(\mathbf{m m H g})$ & $-0.07 \pm 0.33$ \\
DCT & $17.1 \pm 3.3(9.5-26.5)$ \\
NCT (mmHg) & $15.5 \pm 4.2(8-31)$ \\
CNCT (mmHg) & $12.2 \pm 4.3$ \\
OPA (mmHg) & $2.80 \pm 1.15(1.1-7.2)$ \\
CCT ( $\boldsymbol{m m})$ & $563.6 \pm 36.6(472-664)$
\end{tabular}

DCT: dynamic contour tonometry; NCT: non-contact tonometry; $\mathrm{CNCT}$ : corrected non-contact tonometry; OPA: ocular pulse amplitude; CCT: central corneal thickness

Table 1 Characteristics of the 90 eyes included in the study and main results of IOP readings, central corneal thickness and ocular pulse amplitude

\begin{tabular}{cccc}
\hline & $\mathbf{r}$ & $\mathbf{R}^{2}$ & $\mathbf{p}$ \\
\hline NCT & 0.27 & 0.071 & 0.11 \\
CNCT & 0.34 & 0.118 & 0.001 \\
DCT & 0.03 & 0.001 & 0.788 \\
\hline
\end{tabular}

DCT: dynamic contour tonometry; NCT: non-contact tonometry; CNCT: corrected non-contact tonometry;

Table 2. Association between IOP and CCT $(n=90)$

\begin{tabular}{lccccc}
\hline & $\begin{array}{c}\text { Mean }(\mathrm{mmHg}) \pm \\
\mathrm{SD}\end{array}$ & $\begin{array}{c}\text { Mean difference } \\
(\mathrm{mmHg}) \pm \mathrm{SD}\end{array}$ & $\begin{array}{c}\mathrm{S}_{\mathrm{W}} \\
(\mathrm{mmHg})\end{array}$ & $\mathrm{CV}_{\mathrm{W}} \%$ & $\mathrm{ICC}(95 \% \mathrm{Cl})$ \\
\hline DCT - NCT & $16.12 \pm 3.3$ & $1.62 \pm 4.32$ & 2,28 & 14,56 & $0.59(0.445-0.715)$ \\
DCT-CNCT & $14.56 \pm 3.39$ & $4.95 \pm 3.6$ & 3,71 & 28.01 & $0.56(0.399-0.686)$
\end{tabular}

$\mathrm{S}_{\mathrm{w}}$ : within-subject standard deviation; $\mathrm{CV}_{\mathrm{w}}$ : within-subject coefficient of variation; ICC: intra-class correlation coefficient; $\mathrm{Cl}$ : confidence interval; DCT: dynamic contour tonometry; NCT: non-contact tonometry; CNCT: corrected non-contact tonometry.

Table 3. Summary of the IOP concordance analysis $(n=90)$ 


\begin{tabular}{|c|c|c|c|c|c|}
\hline $\begin{array}{c}\text { Reference, } \\
\text { year }\end{array}$ & $\begin{array}{l}\text { tonometer } \\
\text { s }\end{array}$ & $\begin{array}{c}\text { Eyes } \\
\text { (patients) }\end{array}$ & $\begin{array}{l}\mathrm{CCT}(\mu \mathrm{m}) \pm \mathrm{SD} \\
\text { range }\end{array}$ & correlation CCT/IOP & Tonometer's agreement \\
\hline $\begin{array}{l}\text { Kaufmann } \\
\text { et al., } 2004\end{array}$ & DCT/GAT & 228 & {$[439,642]$} & $\begin{array}{l}\text { DCT: } p=0.65 \\
\text { GAT: } p=0.012\end{array}$ & DCT-GAT $=1.7 \mathrm{mmHg}$ \\
\hline $\begin{array}{l}\text { Kamppeter } \\
\text { et al., } 2005\end{array}$ & DCT/GAT & $\begin{array}{c}176 \\
(126)\end{array}$ & $546.25 \pm 37.6$ & $\begin{array}{l}\text { DCT: } p=0.32 \\
\text { GAT: } p=0.036\end{array}$ & $\begin{array}{c}r^{2}=0.905 ; p<0.001 \\
\text { DCT-GAT = } 1.73 \mathrm{mmHg} \\
(p<0.001)\end{array}$ \\
\hline $\begin{array}{c}\text { Kotecha et } \\
\text { al., } 2005\end{array}$ & DCT/GAT & 130 & $\begin{array}{c}556 \pm 36.9 \\
{[468,642]}\end{array}$ & $\begin{array}{c}\text { GAT/DCT IOP differences: } \\
r^{2}=0.05 p=0.01\end{array}$ & GAT-DCT $=-0.7 \mathrm{mmHg}$ \\
\hline $\begin{array}{l}\text { Burvenich et } \\
\text { al., } 2005\end{array}$ & $\mathrm{DCT} / \mathrm{NCT}$ & 294 & $555 \pm 36.4$ & $\begin{array}{l}\text { NCT }: r=0.4994 ; R^{2}=0.2494 \\
\text { DCT }: r=0.0583 ; R^{2}=0.0034\end{array}$ & \\
\hline $\begin{array}{l}\text { Martínez de } \\
\text { la Casa et } \\
\text { al., } 2006\end{array}$ & $\begin{array}{l}\text { DCT/RBT/ } \\
\text { GAT }\end{array}$ & $\begin{array}{l}149 \\
(90)\end{array}$ & & $\begin{array}{l}\text { GAT }: r=0.167 p=0.044 \\
\text { RBT }: r=0.232 p=0.005 \\
\text { DCT }: r=0.003 p=0.970\end{array}$ & $\begin{array}{l}\text { RBT-GAT }=1.4 \mathrm{mmHg} \\
\text { DCT-GAT }=4.4 \mathrm{mmHg} \\
\text { DCT-RBT }=3.4 \mathrm{mmHg}\end{array}$ \\
\hline $\begin{array}{l}\text { Ceruti et al. } \\
2009\end{array}$ & DCT/GAT & 300 & $\begin{array}{c}546 \pm 27.3 \\
543.6 \pm 35.6 \\
553.6 \pm 34.4\end{array}$ & $\begin{array}{l}\text { DCT: } p=0.43 \\
\text { GAT: } P=0.001\end{array}$ & DCT-GAT $=2.6 \mathrm{mmHg}$ \\
\hline $\begin{array}{l}\text { Erdurmus et } \\
\text { al., } 2009\end{array}$ & DCT/NCT & 104 & $563 \pm 45$ & $\begin{array}{l}\text { NCT: } p=0.000 r^{2}=0.301 \\
\text { DCT: } p=0.388 r^{2}=-0.002\end{array}$ & $\begin{array}{l}\text { NCT-DCT }=-0.80 \mathrm{mmHg} \\
\text { LoA }(-6.6 \text { to } 5.1) \mathrm{mmHg}\end{array}$ \\
\hline $\begin{array}{l}\text { Jordao et } \\
\text { al., } 2009\end{array}$ & DCT/GAT & $\begin{array}{l}1000 \\
(500)\end{array}$ & $543.6 \pm 35.4$ & $\begin{array}{l}\text { GAT: } p<0.001 r^{2}=0.28 \\
\text { DCT: } p=0.017 r^{2}=0.01\end{array}$ & DCT-GAT $=3.2 \mathrm{mmHg}$ \\
\hline $\begin{array}{l}\text { Gunvant et } \\
\text { al., } 2010\end{array}$ & DCT/GAT & 120 & & $\begin{array}{l}\text { GAT: } p=0.03 r=0.20 \\
\text { DCT: } p=0.84 r=0.02\end{array}$ & $\begin{array}{c}\text { GAT-DCT } \\
\text { LoA }(-6.9 \text { a } 4.1) \mathrm{mmHg} \\
\text { EGAT-DCT } \\
\text { LoA }(-8.25 \text { a } 4.15) \mathrm{mmHg}\end{array}$ \\
\hline $\begin{array}{l}\text { Sáez- } \\
\text { Francés, } \\
2011 \\
\end{array}$ & DCT/GAT & 63 & $555.08 \pm 31.09$ & GAT: $p=0.04 r^{2}=0.11$ & DCT-GAT $=1.68 \mathrm{mmHg}$ \\
\hline $\begin{array}{l}\text { Colás- } \\
\text { Tomás et } \\
\text { al., } 2012\end{array}$ & $\begin{array}{c}\text { DCT/GAT/ } \\
\text { NT }\end{array}$ & $\begin{array}{l}101 \\
(60)\end{array}$ & $594.5 \pm 30$ & $\begin{array}{c}\text { GAT: } p=0.036 r=0.209 \\
\text { DCT: } p=0.051 r=0.195 \\
\text { NT: } p=0.12 r=0.15\end{array}$ & \\
\hline $\begin{array}{l}\text { Jordao et } \\
\text { al., } 2013\end{array}$ & DCT/GAT & $\begin{array}{c}31 \\
(31)\end{array}$ & $534 \pm 72.3$ & $\begin{array}{c}\text { GAT: } p=0.38 r^{2}<0.001 \\
\text { DCT: } p=0.821 r^{2}=0.0001\end{array}$ & $\begin{array}{c}\text { DCT-GAT } \\
\text { range } 10.45 \mathrm{mmHg}\end{array}$ \\
\hline $\begin{array}{l}\text { Present } \\
\text { study }\end{array}$ & DCT/NCT & $\begin{array}{c}90 \\
(90)\end{array}$ & $563.6 \pm 36.6$ & $\begin{array}{c}\text { DCT: } p=0.788 r^{2}=0.001 \\
\text { NCT: } p=0.11 r^{2}=0.071 \\
\text { CNCT: } p=0.001 r^{2}=0.118\end{array}$ & $\begin{array}{c}\text { DCT-NCT:1.62 } \mathrm{mmHg} \\
\text { LoA(-2.85 to } 6.09) \mathrm{mmHg}\end{array}$ \\
\hline
\end{tabular}

Table 4. Summary of previous studies of the effect of central corneal thickness on dynamic contour tonometry and the main results obtained with different modalities of tonometry. DCT: dynamic contour tonometer; RBT: rebound tonometer; GAT. Goldman applanation tonometer; NT: pneumotonometer; NCT: noncontact tonometer; EGAT: Ehlers-corrected GAT 


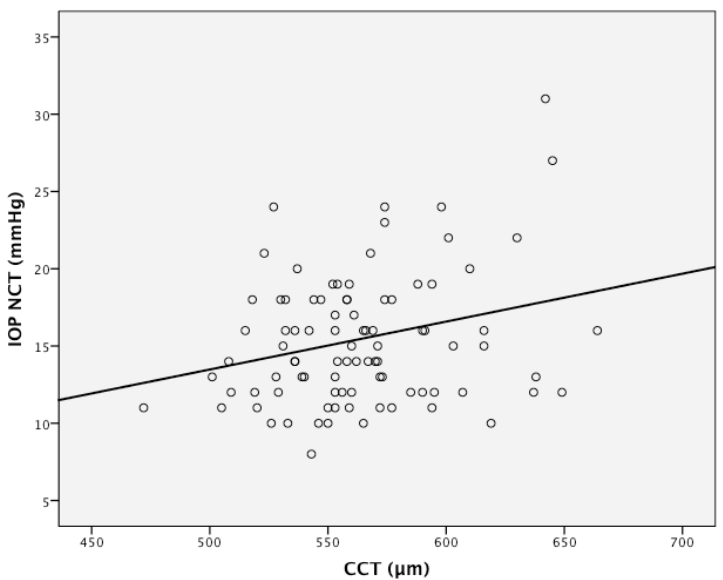

(a)

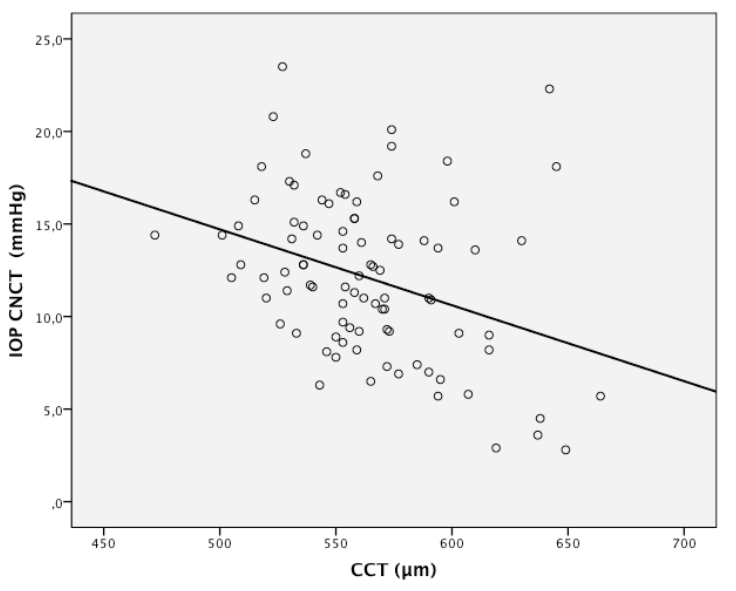

(b)

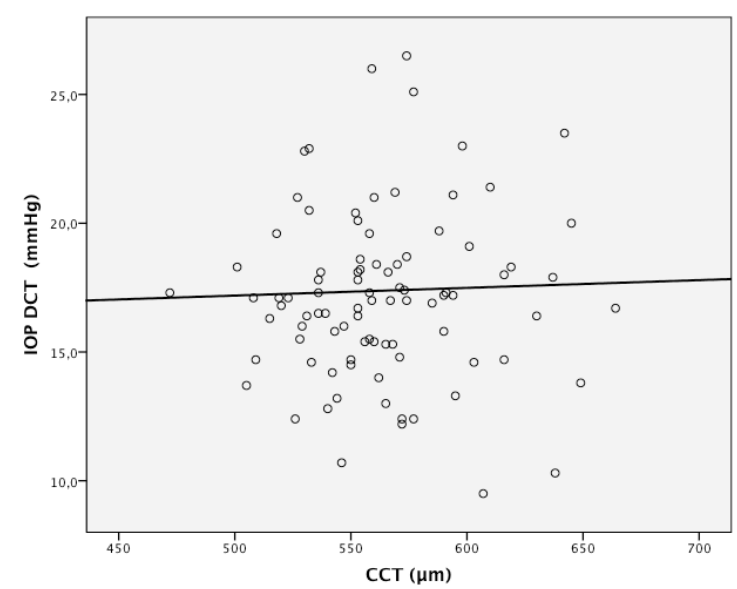

(c)

Figure 1. Scatterplot showing the association between the central corneal thickness and intraocular pressure measured by noncontact tonometer (a), Ehlers corrected noncontact tonometer (b) and Pascal dynamic contour tonometer (c). Trend line indicates positive association between CCT and IOP in (a), negative association in (b) and no association in (c). 

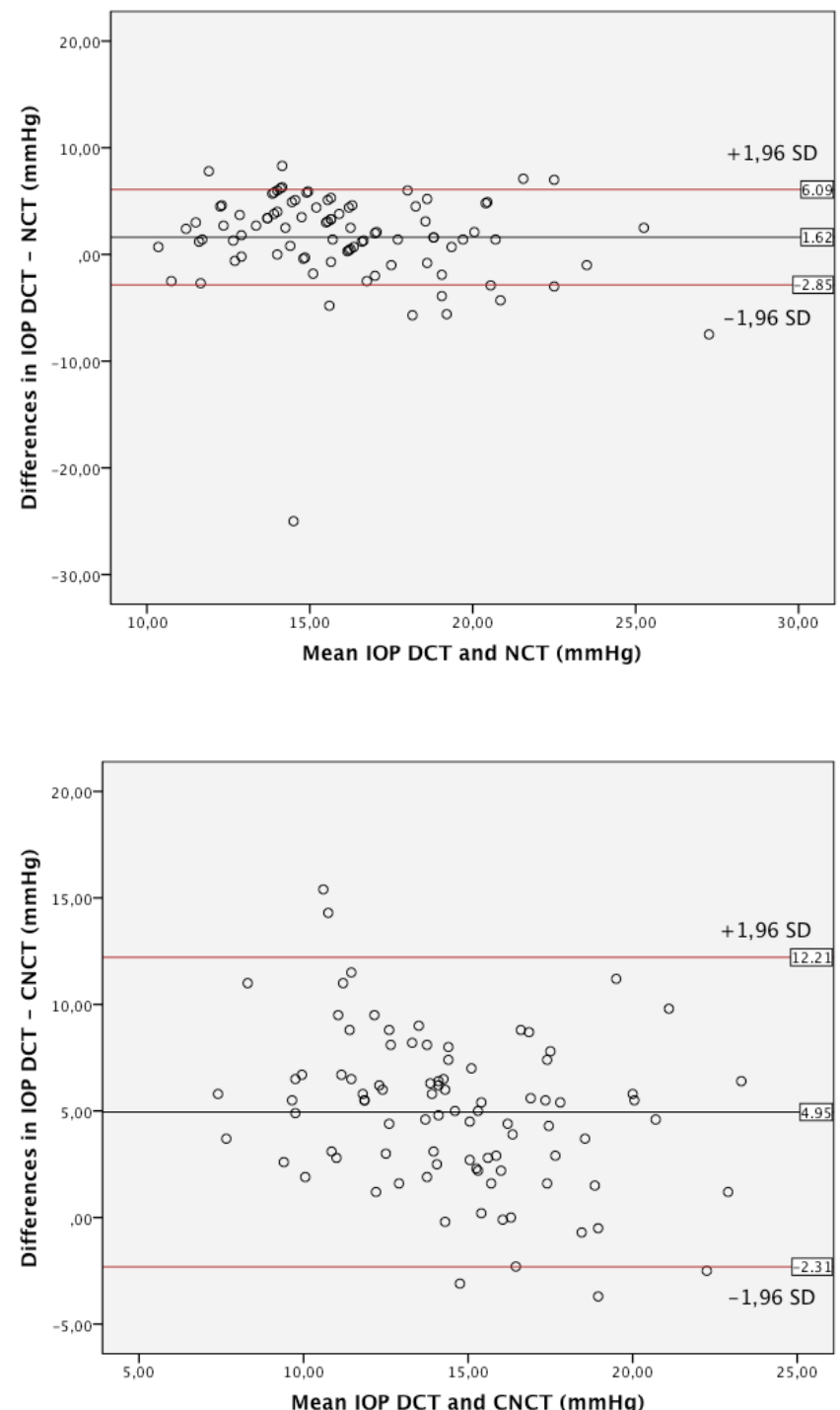

Figure 2. Bland-Altman plot showing the differences in IOP between DCT and CNCT (top) and DCT and CNCT (botton) plotted against the mean value of both. The upper and the lower lines represent the LoA calculated as mean $\pm 1.96 \mathrm{SD}$. 